\title{
Role of colonization in spatio-temporal patchiness of microgastropods in coralline turf habitat
}

\author{
C. Olabarria* \\ Centre for Research on Ecological Impacts of Coastal Cities, Marine Ecology Laboratories A11, \\ University of Sydney, Sydney, NSW 2006, Australia
}

Received 7 January 2002; received in revised form 7 May 2002; accepted 15 May 2002

\begin{abstract}
The ability of benthic macrofauna to disperse and colonize new habitats throughout their life may contribute substantially to small-scale patchiness in abundances in different habitats. Microgastropods in coralline turf on rocky shores in Australia are very patchy in abundance at different spatio-temporal scales. They therefore represent an ideal assemblage for testing hypotheses about processes of colonization. Patterns and rates of colonization of 10 species of microgastropods were investigated in one intertidal habitat (coralline turf) in Botany Bay, New South Wales, Australia, using artificial substrata, which are considered to be a good mimic of natural coralline turfs. The experiment was designed to test the hypotheses that (1) patterns (abundance of colonizing individuals) and mode (juveniles vs. adults) of colonization depends on the proximity of a patch to a potential source of dispersing colonists (i.e. patch of natural coralline turf), (2) different species show different rates of colonization, and (3) patterns of succession are not repeatable among different patches of natural algae. Seven different plots (natural patches of coralline turf) were randomly chosen in the area of study. Artificial units (called patches) were placed at different distances around each plot (within the plot and 0,50 or $100 \mathrm{~cm}$ away from the edge). Samples were collected 6,13, and 27 days after the experiment started. Colonization was rapid (i.e. within 6 days) for most species. Pattern (number of individuals) and mode of colonization (adults vs. juveniles) varied among algal plots. Most species responded differently across patches causing no consistent patterns of colonization. Furthermore, patterns of colonization of artificial units were not always synchronous with, or in the same direction as, changes in abundances in the nearest algal plots, which themselves showed no consistent spatio-temporal pattern. Crown Copyright (C) 2002 Published by Elsevier Science B.V. All rights reserved.
\end{abstract}

Keywords: Australia; Intertidal rocky shore; Microgastropods; Artificial turf; Colonization; Patchiness

\footnotetext{
* Present address: Deep-sea Biology Group, George Deacon Division, Southampton Oceanography Centre, Empress Dock, Southampton SO14 3ZH, UK.

E-mail address: cola@soc.soton.ac.uk (C. Olabarria).
} 


\section{Introduction}

Over the past several years, many ecologists have turned their attention to understanding how ecological processes vary at different spatial and temporal scales (e.g. Dayton and Tegner, 1984; Barry and Dayton, 1991; Dayton et al., 1992; Levin, 1992; Thrush et al., 1996). Ecological communities are commonly affected by disturbances that vary in extent, intensity, and frequency. These disturbances consequently, can have effects that vary in spatial and temporal scale (Hall et al., 1994). Disturbances are often considered to play a central role in dynamics of assemblages by creating a mosaic of patches at different stages of recovery (Van Blaricom, 1982; Underwood, 1999). To understand and model the functioning of mosaics of patches (e.g. Paine and Levin, 1981), one must understand the mechanisms and rates of arrival of new organisms into disturbed patches.

Although benthic marine research has emphasized species that colonize areas as planktonic larvae, individuals of many taxa disperse as adults and/or juveniles (e.g. Santos and Simon, 1980; Highsmith, 1985; Martel and Chia, 1991; Norkko et al., 2001). The ability of benthic macrofauna to disperse throughout their life may contribute substantially to species reacting to local heterogeneity of habitats (Günther, 1992). High rates of postsettlement movement are considered important in providing a mechanism for rapid dispersal and recolonization of patches by macrofauna, contributing to small-scale patchiness in different habitats (Cummings et al., 1995). Recent research has shown that some macrofauna and meiofauna are highly mobile as adults. Many benthic species undertake regular nocturnal excursions into the water column (Ohlhorst, 1982; Howard, 1985) and defaunated sites often may be colonized within a few hours, days or weeks (Sherman and Coull, 1980; Leber, 1985; Virnstein and Curran, 1986). In addition, transport of bedload and suspended load may move post-settlement juvenile and adult benthic stages of softbottom macrofauna, particularly bivalves and gastropods (e.g. Sörlin, 1988; Highsmith, 1985; Commito et al., 1995; Cummings et al., 1995; Norkko et al., 2001). It is now widely recognized that above-sediment movement by post-settlement macrofauna is an important process structuring soft-sediment systems and can have a significant influence on patterns of macrofaunal distribution and abundance (Günther, 1992; Snelgrove et al., 1993).

Therefore, knowledge of the ability of macrofauna at different stages of their life cycles to colonize new habitats is generally important in determining responses of assemblages to disturbance. Experiments investigating colonization may provide useful information about rates of movement into unoccupied habitat (Bell and Devlin, 1983; Howard, 1985) and can be used to measure distances over, which fauna can disperse.

Studies of colonization have primarily focused on macrofauna in soft-bottom communities (e.g. Sherman and Coull, 1980; Zajac and Whitlatch, 1982; Bell and Devlin, 1983; Virnstein and Curran, 1986; Thrush et al., 1996; Turner et al., 1997) or large components of the fauna on rocky intertidal habitats (e.g. McGuinness, 1988; Lagadeuc and Colbeaux, 1992; Hockey and Schurink, 1992; Davenport and Stevenson, 1998). To date, relatively little attention has been paid to the influence of colonization on the population dynamics of microfauna on intertidal rocky shores.

Microfaunal assemblages have great potential for measuring changes to biodiversity (Gee and Warwick, 1996) and assessing environmental impacts (Smith and Simpson, 1993). A diverse assemblage can be found in small patches of habitat under different 
environmental conditions and can develop in both natural and artificial habitats placed in different areas (Gee and Warwick, 1996). Coralline turfs (i.e. turfs composed of tightly packed upright branches of coralline algae, forming a stiff matrix that holds quantities of sand) are a common type of habitat on rocky shores in Australia. Microgastropods (i.e. gastropods with adult size $<2 \mathrm{~mm}$ ) are a common component of assemblage in algal turf. As their abundances are patchy at different spatial (Olabarria and Chapman, 2001a) and temporal scales (Olabarria and Chapman, 2002), they represent an ideal assemblage to test models of ecological processes, including colonization. Particularly, abundances of microgastropods vary largely at small spatial scale in coralline turf habitat (Olabarria and Chapman, 2001a). This variation may be caused by processes of recruitment and/or mortality (Underwood and McFadyen, 1983) or short-term dynamic patterns of immigration and emigration among patches of habitat (Barnes, 1998). Because coralline turfs range from beds of algae that extend over several hundreds of meters, to fragmented patches $<0.25 \mathrm{~m}^{2}$ (Stewart, 1982; Akioka et al., 1999), coralline turf is, therefore, an ideal system for evaluating the role of colonization in determining patterns of distribution in fragmented habitats.

Until now, studies on patch dynamics of soft-sediment (reviewed by Thrush et al., 1996) and intertidal rocky shores (reviewed by Sousa, 1985) have focused primarily on the influence of the size, shape, and location of the patch on colonization and changes in colonization overtime (i.e. succession) (Virnstein and Curran, 1986; Farrell, 1991; Benedetti-Cecchi and Cinelli, 1994). For example, a patch's position with respect to various environmental gradients (tidal height, velocity of currents, degree of insolation) can influence greatly the mode and rate of colonization (e.g. Denley and Underwood, 1979).

To my knowledge, not much attention has been paid to the location of patches on succession of microfaunal assemblages in algal beds on rocky shores (but see Dean and Connell, 1987a,b). In this study, colonization of artificial patches of turf by species of microgastropods that normally inhabit coralline turfs is documented. Habitat-mimics, such as artificial turf possess similar structural characteristics to natural habitat, but do not exhibit any of the biological characteristics of natural habitats. Various types of habitatmimics have been used to test hypotheses about faunal assemblages associated with different habitats on rocky intertidal shores (e.g. Myers and Southgate, 1980; Davenport and Stevenson, 1998). Artificial patches of coralline turf provide a good mimic of natural algal turf and avoid potential artefacts associated with defaunating natural coralline turf to measure colonization and confounding effects, such as shape or size of patch because patches can be made to measure. These patches also accumulate sediment as the natural algal turf, but it is very dynamic over time (Kelaher, 2000). Moreover, artificial turfs are colonized by a similar suite of species as are found in natural habitats (Bell and Hicks, 1991; Edgar, 1991).

The microgastropods used in this study represented different species within a range of families, with likely different life-history traits with respect to feeding modes, reproduction, development, mobility, and dispersal (Beesley et al., 1998). Life histories and the stage of the life cycle which disperses, can change rates or patterns of colonization (Smith and Brumsickle, 1989). For example, organisms that disperse over long distances may colonize small, isolated patches more efficiently than do individuals with limited dispersal ability (Sousa, 1984; Butler, 1991, but see Johannesson, 1988). 
This experimental study was designed to test the hypotheses that (1) patterns (i.e. abundance of colonizing individuals) and mode of colonization (i.e. juveniles vs. adults) depend on the proximity of a patch to a potential source of dispersing colonists (i.e. a patch of natural coralline turf), (2) different species show different rates of colonization, and (3) patterns of succession (i.e. sequence of arrival of each species) are not repeatable among patches of natural coralline turf because of variability in physical and biological processes experienced by each patch.

\section{Material and methods}

\subsection{Study area}

The experiment was done in the Cape Banks Scientific Marine Research Area on the northern headland of Botany Bay, New South Wales, Australia (site described in Olabarria and Chapman, 2001a). The area $\left(\sim 1500 \mathrm{~m}^{2}\right)$ was orientated to the west with a slope of $30^{\circ}$ and was semiexposed to wave-action. This intertidal rock platform had many patches of coralline turf, composed of tightly packed upright branches of coralline algae, primarily Corallina officinalis Linnaeus, forming a stiff matrix that held quantities of sand. Patches of turf separated by distances ranging from tens of centimeters to $10 \mathrm{~m}$ were isolated from each other by what appeared as bare rock to the naked eye. These patches were about 1 to $2.5 \mathrm{~m}^{2}$ and were between mid- and low-shore, ranging from 0.29 to $0.96 \mathrm{~m}$ above mean lower low water (MLLW). Although the swell is predominantly from one direction in the study area, swell was not large over the time of this experiment and most of the wave-swash was to and from.

\subsection{Experimental design and sampling}

Artificial turfs (manufactured by the Grass Alternative, Sydney) were made of polypropylene strips attached in regular rows to a latex back. The rows of fronds were separated by $10 \mathrm{~mm}$, the bundles of fronds in each row were $6 \mathrm{~mm}$ apart and the fronds were $26 \mathrm{~mm}$ in length. PVC pipe-ends, which were $10 \mathrm{~cm}$ in diameter $\left(78.5 \mathrm{~cm}^{2}\right)$ and had $3 \mathrm{~cm}$ high sides, were screwed to the rock. A similar sized patch of artificial turf was glued in each pipe-end using epoxy resin. To avoid possible effects of chemicals on colonization, pipe-ends and patches of artificial turf were soaked in seawater for 1 week prior to being placed in the field.

The experiment was in the field from June 8 to July 5, 2001. Seven plots of natural coralline turf, separated by at least $6 \mathrm{~m}$, were randomly chosen in the area of study. Use of replicate plots tested for generality of patterns across different patches of turf. Units of artificial turf (i.e. patches) were placed at different distances around or in each natural plot. Distances were chosen to represent a set of those natural distances (see Section 2.1) and were relevant to models about how these small snails move among natural patches of algae. These distances also represented those, in which spatial variability in abundances of microgastropods had been previously found (Olabarria and Chapman, 2001a). Artificial patches placed within the natural plot, i.e. a procedural control, examined colonization of 
artificial structures when species could potentially colonize those patches from the surrounding habitat. Those placed on the edge $(0 \mathrm{~cm})$, at 50 or at $100 \mathrm{~cm}$ from the natural coralline plot tested the hypotheses that patterns and mode of colonization vary with the proximity of a patch to a potential source of colonists. Microgastropods have not been observed on the bare rock among the patches of algae and are unlikely to be able to crawl 50 or $100 \mathrm{~cm}$ on these surfaces. At each distance from the plot, the patches were placed $8 \mathrm{~cm}$ apart in a line parallel to the border between the patch of coralline turf and the surrounding area and located at the same height as the coralline turf. To measure normal abundances of snails in each natural coralline plot, $10 \mathrm{~cm}$ in diameter core was pushed into the turf and the algae and sediment inside the core scraped off at the level of the rock. After 6, 13, and 27 days, two replicate patches from randomly assigned positions at each distance and two replicate cores from natural coralline turf were collected.

The number of replicates was small $(n=2)$, but it was the most appropriate compromise between the increase of number of replicates to get more powerful tests and time required to sort each sample. Moreover, it was decided to put the effort into maximizing the number of plots (i.e. seven patches of natural coralline turf) because a previous work showed lots of plot-to-plot variation (Olabarria and Chapman, 2002).

Samples were fixed in 7\% formalin in seawater and sieved through a $63 \mu \mathrm{m}$ mesh. Then, organisms from each sample were counted and assigned as juveniles $(<0.5 \mathrm{~mm})$ or adults $(>0.5 \mathrm{~mm})$ under the microscope. Ten species of microgastropods, most direct developers with one that has larval dispersal (Beesley et al., 1998), were selected for analysis. These microgastropods only represented a small component of the assemblage (e.g. Kelaher, 2000 showed 102 macrofaunal taxa in coralline turf), but they were relatively abundant in algal turf (Olabarria and Chapman, 2001a) and represented species across a range of families (Table 1).

\subsection{Analysis of data}

To test the hypotheses that (1) patterns of colonization depend on the proximity of a patch to the potential source of colonists (coralline algal turf), and (2) different species show different rates of colonization, abundances of each species were separately analysed using

Table 1

The taxonomic relationships and type of development (Beesley et al., 1998) of the species of microgastropods selected for this study

\begin{tabular}{|c|c|c|c|}
\hline Superfamily & Development & Family & Species \\
\hline Trochoidea & Larval dispersal? & Turbinidae & Tricolia variabilis (Pease, 1861) \\
\hline \multirow[t]{4}{*}{ Cingulopsoidea } & Direct development & \multirow[t]{2}{*}{ Eatoniellidae } & Eatoniella atropurpurea (Frauenfeld, 1867) \\
\hline & Direct development & & Crassitoniella flammea (Frauenfeld, 1867) \\
\hline & Direct development & \multirow[t]{2}{*}{ Cingulopsidae } & Eatonina rubrilabiata Ponder and Yoo, 1980 \\
\hline & Direct development & & Pseudopisinna gregaria gregaria Laseron, 1950 \\
\hline \multirow[t]{4}{*}{ Rissooidea } & Direct development & \multirow[t]{4}{*}{ Anabathridae } & Amphithalamus incidata (Frauenfeld, 1867) \\
\hline & Direct development & & Scrobs luteofuscus (May, 1919) \\
\hline & Direct development & & Pisinna olivacea (Frauenfeld, 1867) \\
\hline & Direct development & & Anabathron contabulatum (Frauenfeld, 1867) \\
\hline Omalogyroidea & Direct development & Omalogyridae & Omalogyra liliputia (Laseron, 1954) \\
\hline
\end{tabular}


three-way mixed model ANOVAs. Treatment (five levels: natural turf, procedural control, 0 , 50 and $100 \mathrm{~cm}$ ) and Time, since start of experiment (three levels: 6, 13 and 27 days), were fixed factors and Plot (seven levels, i.e. patches of natural turf) was a random factor.

Five species, Eatoniella atropurpurea, Eatonina rubrilabiata, Pseudopisinna gregaria gregaria, Amphithalamus incidata, and Scrobs luteofuscus, which were sufficiently abundant and had adults and juveniles in the samples, were also analysed using Life stage (juvenile vs. adult) as a 4th fixed factor to test the hypothesis that mode of colonization varies with the proximity of a patch to a potential source of colonists, i.e. adults and juveniles show different patterns. There was, however, a problem of non-independence of data due to juveniles and adults came from the same samples. As the number of replicates was two, adults and juveniles from different replicates could not be analysed using a model, where all factors were orthogonal. Consequently, data were analysed using 4-factor ANOVAs with Stage, Treatment and Time as orthogonal and fixed factors, and Plot (six levels, i.e. only six patches of natural turf) as a random factor nested within Stage and orthogonal to Time and Treatment.

Homogeneity of variances was examined using Cochran's test and data were logtransformed to eliminate heterogeneity. Data for all species were transformed because it was desirable to analyse all species in a similar scale to facilitate comparisons across species. Analyses of variance were followed by a posteriori Student-Newman-Keuls tests (SNK tests) on appropriate terms of the model found to be significant.

Additional analyses of total abundance (i.e. across species) over time and over the spatial scales of the study together with multivariate analyses (Warwick, 1993) of the 10 species were performed, but results did not provide additional insight into assemblage-level interactions.

Mean abundances of most species (E. atropurpurea, P. g. gregaria, A. incidata, $S$. luteofuscus, Anabathron contabulatum and Omalogyra liliputia) varied significantly among treatments (see Results), but this variation was not consistent across plots and/or from time to time. Subsequent multiple comparisons were not always able to identify, which treatments differed consistently across plots and times. The differences in the frequency with which treatments were given a particular rank by SNK tests in a series of multiple comparisons for each species, time and plot were recorded. If any treatment showed a particular tendency to have larger mean abundances in a series of multiple comparisons, that treatment would repeatedly have a larger rank than would the other treatments. These ranks were then analysed using the Anderson's test (Winer, 1971), to test the hypothesis that any particular treatment consistently ranked larger.

\section{Results}

\subsection{Natural coralline turf}

Five species, E. atropurpurea, E. rubrilabiata, $P$. g. gregaria, A. incidata and $S$. luteofuscus, were the most abundant and widespread across different plots of coralline turf. The abundance of each species varied across plots and through time. There was no clear temporal trend in abundances for most species, and patterns of change (increases or 
decreases) were not in the same direction in the different plots (Fig. 1a-b; illustrated by $E$. atropurpurea and $S$. luteofuscus; Time $\times$ Plot, $F_{12,21}=2.29, P<0.05 ; F_{12,21}=2.32$, $P<0.05$, respectively). Only one species, $O$. liliputia, showed a similar temporal trend across plots, with larger abundances at time 3 (i.e. after 27 days) (Fig. $1 \mathrm{c}$; Time, $F_{2,12}=6.89$, $P<0.01)$ ). Other species were not found in all of the plots and/or times of sampling and their abundances were small (Fig. 1d, illustrated by Crassitoniella flammea; all $F$ ratios $P>0.05$ ).

\subsection{Pattern and mode of colonization. Distance from the potential source of colonists}

In general, independently of distance from the plot, all the artificial patches were colonized, reaching similar or larger abundances to those in the natural coralline turf. Pattern of colonization varied, however, among species, across plots and from time to time.

Four species, Tricolia variabilis, C. flammea, E. rubrilabiata, and Pisinna olivacea showed no significant variation among treatments, i.e. distance from the plot, nor interactions between treatment and plot or time (Table 2). The abundances of these species in all patches were similar to those in the natural turfs (illustrated for E. rubrilabiata in four plots; Fig. 2a).

P.g. gregaria and O. liliputia showed significant differences among treatments, which were not consistent across plots (i.e. interaction Treatment $\times$ Plot; Table 2). SNK tests
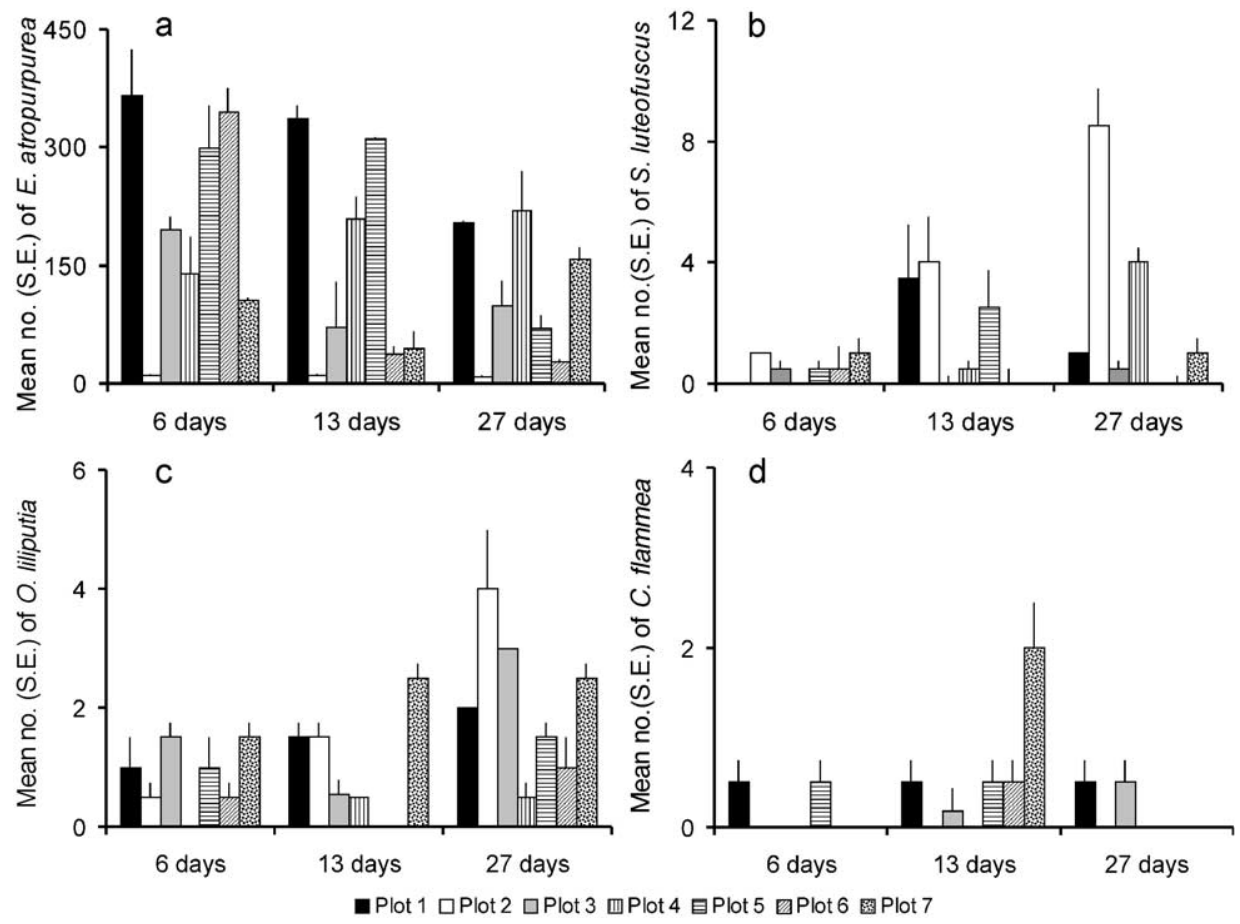

Fig. 1. Mean number ( $\pm \mathrm{SE}$ ) of individuals $(n=2)$ of (a) E. atropurpurea, (b) S. luteofuscus, (c) O. liliputia, (d) C. flammea in the natural coralline turfs (Plot 1-Plot 7) after 6, 13, and 27 days. 
Table 2

Summary of ANOVA for abundance of each species

\begin{tabular}{|c|c|c|c|c|c|c|c|c|c|c|c|}
\hline Source & $d f$ & T. variabilis & E. atropurpurea & C. flammea & E. rubrilabiata & P. g. gregaria & A. incidata & S. luteofuscus & P. olivacea & A. contabulatum & O. liliputic \\
\hline Time $=\mathrm{Ti}$ & 2 & $3.82^{\text {n.s. }}$ & $8.70 * *$ & $0.78^{\text {n.s. }}$ & $6.44 * *$ & $5.35 *$ & $36.47 * * *$ & $35.64 * * *$ & $29.64 * * *$ & $4.61 *$ & $23.77 * * *$ \\
\hline Plot $=$ Pl & 6 & $8.37 * * *$ & $8.68 * * *$ & $1.41^{\text {n.s. }}$ & $5.63 * * *$ & $10.99 * * *$ & $11.00 * * *$ & $7.93 * * *$ & $4.41 * * *$ & $4.64 * * *$ & $7.26 * * *$ \\
\hline Treatment $=\mathrm{Tr}$ & 4 & $0.90^{\text {n.s. }}$ & $15.99 * * *$ & $1.51^{\text {n.s. }}$ & $0.75^{\text {n.s. }}$ & $0.70^{\text {n.s. }}$ & $3.51 *$ & $21.06 * * *$ & $0.68^{\text {n.s. }}$ & $0.69^{\text {n.s. }}$ & $1.68^{\text {n.s. }}$ \\
\hline $\mathrm{Ti} \times \mathrm{Pl}$ & 12 & $2.27 *$ & $0.51^{\text {n.s. }}$ & $2.26 *$ & $1.10^{\text {n.s. }}$ & $1.77^{\text {n.s. }}$ & $0.77^{\text {n.s. }}$ & $2.01^{\text {n.s. }}$ & $0.59^{\text {n.s. }}$ & $0.82^{\text {n.s. }}$ & $0.96^{\text {n.s. }}$ \\
\hline $\mathrm{Ti} \times \operatorname{Tr}$ & 8 & $1.25^{\text {n.s. }}$ & $2.95 * *$ & $1.98^{\text {n.s. }}$ & $1.33^{\text {n.s. }}$ & $2.06^{\text {n.s. }}$ & $3.03 * *$ & $2.75^{*}$ & $0.95^{\text {n.s. }}$ & $1.13^{\text {n.s. }}$ & $1.61^{\text {n.s. }}$ \\
\hline $\mathrm{Pl} \times \operatorname{Tr}$ & 24 & $0.73^{\text {n.s. }}$ & $4.11 * * *$ & $1.41^{\text {n.s. }}$ & $0.91^{\text {n.s. }}$ & $3.12 * * *$ & $1.24^{\text {n.s. }}$ & $1.34^{\text {n.s. }}$ & $1.50^{\text {n.s. }}$ & $1.81 *$ & $1.78 *$ \\
\hline $\mathrm{Ti} \times \mathrm{Pl} \times \mathrm{Tr}$ & 48 & $0.59^{\text {n.s. }}$ & $1.42 *$ & $0.87^{\text {n.s. }}$ & $1.30^{\text {n.s. }}$ & $1.02^{\text {n.s. }}$ & $1.22^{\text {n.s. }}$ & $0.94^{\text {n.s. }}$ & $1.03^{\text {n.s. }}$ & $1.51 *$ & $1.31^{\text {n.s. }}$ \\
\hline
\end{tabular}

Residual $\quad 105$

$F$-ratios and level of significance are shown $(n=2)$. Time (three levels: 6,13 and 27 days) and Treatments (five levels: natural turf, procedural control, 0,50 and $100 \mathrm{~cm}$ ) are fixed factors; Plot (seven levels: natural coralline turf) is a random factor. $* P<0.05, * * P<0.01, * * * P<0.001$, n.s. $P>0.05$. 

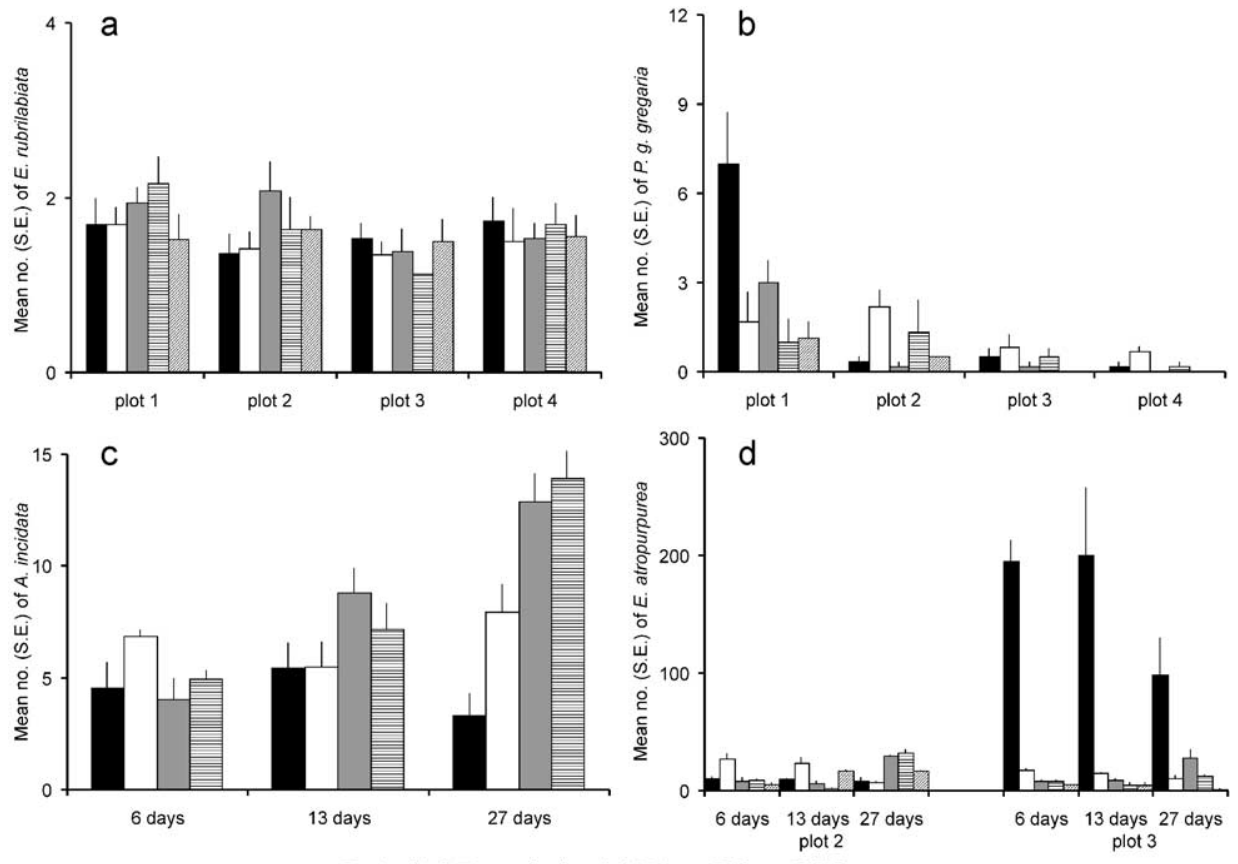

- natural turf $\square$ procedural control $\square 0 \mathrm{~cm}$ 目 $50 \mathrm{~cm} \square 100 \mathrm{~cm}$

Fig. 2. Mean number $( \pm \mathrm{SE})$ of individuals $(n=2)$ in each treatment (natural turf, procedural control, 0,50 , and $100 \mathrm{~cm}$ ). (a) E. rubrilabiata in Plot 1-Plot 4, (b) P. g. gregaria in Plot 1-Plot 4, (c) A. incidata averaged across plots after 6, 13, and 27 days, (d) E. atropurpurea in Plot 2 and Plot 3 after 6, 13, and 27 days.

showed that abundances of $P$. $g$. gregaria in natural turf were larger than in the other treatments in Plot 1, whereas abundances in the procedural control patches were larger only in Plot 2 (SNK tests, $P<0.05$ ). In the other plots, patches were not significantly different (illustrated for four plots in Fig. 2b). Abundances of O. liliputia were significantly smaller in patches located at $100 \mathrm{~cm}$ than in the other patches only in Plot 7 (SNK test, $P<0.05$ ), but there were no significant differences in the other plots.

A. incidata and $S$. luteofuscus showed significant differences among treatments, which were inconsistent through time (i.e. a significant interaction Treatment $\times$ Time; Table 2). After 27 days, $A$. incidata was less abundant in the natural turf than in all the artificial patches (SNK tests, $P<0.05$; Fig. 2c). After 13 and 27 days, S. luteofuscus also had the smallest abundances in the natural turfs (SNK tests, $P<0.05$ ).

Finally, A. contabulatum and E. atropurpurea showed significant differences among treatments, i.e. distance from the plot, but these differences varied across plots and with length of time (Table 2). After 6 and 13 days, abundances of A. contabulatum were significantly larger in the natural turf than in the other treatments only in Plot 1 (SNK tests, $P<0.05)$. E. atropurpurea, in contrast, was significantly more abundant in the natural turf than in the other treatments (except in Plot 2), although the magnitude of those differences was not consistent across plots and time (illustrated for two plots in Fig. 2d; SNK tests, $P<0.05)$. 
Anderson's tests showed that there were some general trends in variation of treatments across different plots and/or times. These trends, however, varied among different species. Abundances of $P$. g. gregaria and O. liliputia were more often larger in procedural control than in the other treatments within the 28 combinations of treatment and plot (Anderson test, $Q^{2}=62.83, d f=16, P<0.001 ; Q^{2}=108.54, d f=16, P<0.001$, respectively; Table 3). Procedural control (Anderson test, $Q^{2}=93.92, d f=16, P<0.001$ ) and patches located at 0 cm (Anderson test, $Q^{2}=146.66, d f=16, P<0.001$ ) had larger abundances of individuals significantly more often than any other treatment for A. incidata and S. luteofuscus, respectively (Table 3 ). For $A$. contabulatum, there was a significant trend for the natural turf treatment to have the smallest rank across plots at the three different times, whereas patches located at 50 and $100 \mathrm{~cm}$ had the largest rank, i.e. the largest mean abundances (Anderson test, $108.55<Q^{2}<182.83, d f=16, P<0.001$; Table 3). For E. atropurpurea, in contrast, the natural turf treatment had the largest abundances consistently in all comparisons (Anderson test, $145.69<Q^{2}<188.55, d f=16, P<0.001$; Table 3). Thus, the interaction resulted from variation among other treatments (procedural control, 0,50 , and $100 \mathrm{~cm}$ ) across plots and time (e.g. Plot 2 and Plot 3; Fig. 2d).

Adults and juveniles of $P$. g. gregaria, A. incidata, and $S$. luteofuscus showed similar patterns, colonizing all the patches regardless of their distance from the coralline turf (i.e. no significant effect of Stage or interactions between Stage and any other factor; Table 4). In contrast, there was an effect of the life stage in patterns of colonization of $E$. rubrilabiata and E. atropurpurea. E. rubrilabiata showed a significant effect of Stage (Table 4). Adults of this species were more abundant than juveniles in all patches (SNK tests, $P<0.05)$. E. atropurpurea showed significant differences in abundances of juveniles or adults across patches (i.e. significant interaction Stage $\times$ Treatment; Table 4). For example, juveniles were more abundant than adults in patches located at $100 \mathrm{~cm}$ (SNK tests, $P<0.05)$. Abundances of juveniles or adults also varied from time to time. After 27 days, juveniles were more abundant than adults in all patches.

Table 3

Summary of the rank orders (largest and smallest) of frequencies with which treatments were given a particular rank by SNK test in a series of multiple comparisons

\begin{tabular}{|c|c|c|c|c|c|c|c|c|c|c|}
\hline & NT & $\mathrm{PC}$ & D0 & D50 & D100 & NT & $\mathrm{PC}$ & D0 & D50 & D100 \\
\hline & RL & RL & RL & RL & RL & $\mathrm{RS}$ & RS & RS & $\mathrm{RS}$ & $\mathrm{RS}$ \\
\hline E. atropurpurea & 68 & 8 & 4 & 4 & 0 & 8 & 8 & 8 & 24 & 36 \\
\hline P. g. gregaria & 4 & 12 & 8 & 4 & 0 & 8 & 0 & 7 & 4 & 4 \\
\hline A. incidata & 0 & 8 & 0 & 4 & 0 & 8 & 0 & 0 & 0 & 4 \\
\hline S. luteofuscus & 0 & 4 & 4 & 2 & 0 & 12 & 0 & 0 & 0 & 4 \\
\hline A. contabulatum & 12 & 12 & 4 & 16 & 32 & 64 & 4 & 12 & 4 & 0 \\
\hline O. liliputia & 4 & 12 & 8 & 4 & 0 & 16 & 0 & 0 & 0 & 12 \\
\hline
\end{tabular}

There were five treatments (natural turf, NT; procedural control, PC; $0 \mathrm{~cm}, \mathrm{D} 0 ; 50 \mathrm{~cm}, \mathrm{D} 50 ; 100 \mathrm{~cm}, \mathrm{D} 100$ ) ranked 12 times for $A$. incidata, and $S$. luteofuscus, 28 times for $P$. g. gregaria and O. liliputia and 84 times for $E$. atropurpurea and A. contabulatum). RL (largest rank), RS (smallest rank). 
Table 4

Summary of ANOVA

\begin{tabular}{lrccccc}
\hline Source & $d f$ & E. atropurpurea & E. rubrilabiata & P. g. gregaria & A. incidata & S. luteofuscus \\
\hline Stage $=\mathrm{St}$ & 1 & $1.16^{\text {n.s. }}$ & $5.06^{*}$ & $3.23^{\text {n.s. }}$ & $0.23^{\text {n.s. }}$ & $0.02^{\text {n.s. }}$ \\
Time $=\mathrm{Ti}$ & 2 & $10.96^{* * *}$ & $11.54^{* * *}$ & $4.65^{*}$ & $13.02^{* * *}$ & $27.51^{* * *}$ \\
$\mathrm{Plot}(\mathrm{Stage})=\mathrm{Pl}(\mathrm{St})$ & 10 & $3.55^{* * *}$ & $4.15^{* * *}$ & $12.74^{* * *}$ & $1.92^{*}$ & $0.83^{\text {n.s. }}$ \\
Treatment $=\mathrm{Tr}$ & 4 & $14.87^{* * *}$ & $1.33^{\text {n.s. }}$ & $0.92^{\text {n.s. }}$ & $2.56^{\text {n.s. }}$ & $2.84^{*}$ \\
$\mathrm{St} \times \mathrm{Ti}$ & 2 & $7.06^{* *}$ & $0.57^{\text {n.s. }}$ & $0.64^{\text {n.s. }}$ & $0.44^{\text {n.s. }}$ & $1.15^{\text {n.s. }}$ \\
$\mathrm{St} \times \mathrm{Tr}$ & 4 & $3.28^{*}$ & $1.46^{\text {n.s. }}$ & $0.16^{\text {n.s. }}$ & $0.38^{\text {n.s. }}$ & $2.05^{\text {n.s. }}$ \\
$\mathrm{Ti} \times \mathrm{Pl}(\mathrm{St})$ & 20 & $0.55^{\text {n.s. }}$ & $0.90^{\text {n.s. }}$ & $1.44^{\text {n.s. }}$ & $0.47^{\text {n.s. }}$ & $0.34^{\text {n.s. }}$ \\
$\mathrm{Ti} \times \mathrm{Tr}$ & 8 & $5.48^{* * *}$ & $1.70^{\text {n.s. }}$ & $2.23^{*}$ & $1.27^{*}$ & $1.34^{\text {n.s. }}$ \\
$\mathrm{Tr} \times \mathrm{Pl}(\mathrm{St})$ & 40 & $2.67^{* * *}$ & $0.62^{\text {n.s. }}$ & $3.67^{* * *}$ & $0.61^{\text {n.s. }}$ & $0.35^{\text {n.s. }}$ \\
$\mathrm{St} \times \mathrm{Ti} \times \mathrm{Tr}$ & 8 & $1.17^{\text {n.s. }}$ & $0.59^{\text {n.s. }}$ & $1.30^{\text {n.s. }}$ & $0.54^{\text {n.s. }}$ & $1.19^{\text {n.s. }}$ \\
$\mathrm{Tr} \times \mathrm{Ti} \times \mathrm{Pl}(\mathrm{St})$ & 80 & $1.04^{\text {n.s. }}$ & $1.04^{\text {n.s. }}$ & $1.22^{\text {n.s. }}$ & $0.52^{* * *}$ & $0.34^{* * *}$ \\
$\mathrm{Re} \mathrm{Tidual}$ & 180 & & & & & \\
\hline
\end{tabular}

$F$-ratios and level of significance are shown $(n=2)$. Life-stage (two levels: adults and juveniles), Time (three levels: 6,13 , and 27 days) and Treatment (five levels: natural turf, procedural control, 0, 50 and $100 \mathrm{~cm}$ ) are orthogonal and fixed factors; Plot (six levels) is a random factor nested within life-stage. $* P<0.05, * * P<0.01, * * * P<0.001$, n.s. $P>0.05$.

\subsection{Rate of colonization and patterns of abundance overtime}

Colonization of artificial units, in general, was rapid (i.e. within 6 days) for most of the species. Nevertheless, different species showed different temporal trends in patterns of abundance.

E. rubrilabiata, P. g. gregaria, P. olivacea, and O. liliputia colonized all patches within 6 days, but patterns of abundance changed from time to time consistently among plots (i.e. no significant interaction Time $\times$ Plot; see Table 2). E. rubrilabiata and $P$. g. gregaria showed steady increase of abundance from time to time $(6<13<27$ days; SNK tests, $P<0.05)$, whereas abundances of $P$. olivacea and $O$. liliputia were significantly larger after 27 days (SNK tests, $P<0.05$; illustrated by $O$. liliputia in Fig. 3a). In contrast, $T$. variabilis and $C$. flammea colonized all patches (reaching similar abundances to those in natural turfs), but patterns of abundance changed from time to time, inconsistently across plots. For example, in Plot 1 and Plot 2, abundances of T. variabilis were significantly larger after 13 days, but not in the other plots. In one plot (Plot 7), C. flammea had significantly larger abundances after 13 days than after 6 or 27 days (illustrated for Plot 7 in Fig. 3b).

$S$. luteofuscus and $A$. incidata colonized all new patches very quickly, but patterns of abundances in some patches were not stable through time (i.e. significant interaction Time $\times$ Treatment). Abundances of these species in all patches rose to significantly greater numbers than found in natural turfs after 13 and 27 days, respectively (illustrated by $A$. incidata; Fig. 2c).

A. contabulatum and E. atropurpurea showed complex patterns (i.e. significant interaction Time $\times$ Plot $\times$ Treatment; Table 2). Although both species colonized most patches quickly (within 6 days), there were, however, some exceptions. Moreover, patterns of abundance in some patches varied inconsistently across plots and from time to time. For example, after 6 days, E. atropurpurea had only colonized patches in a few plots (e.g. Plot 2, Fig. 2d). Many of the patches did not attain abundances found in natural turfs (SNK 

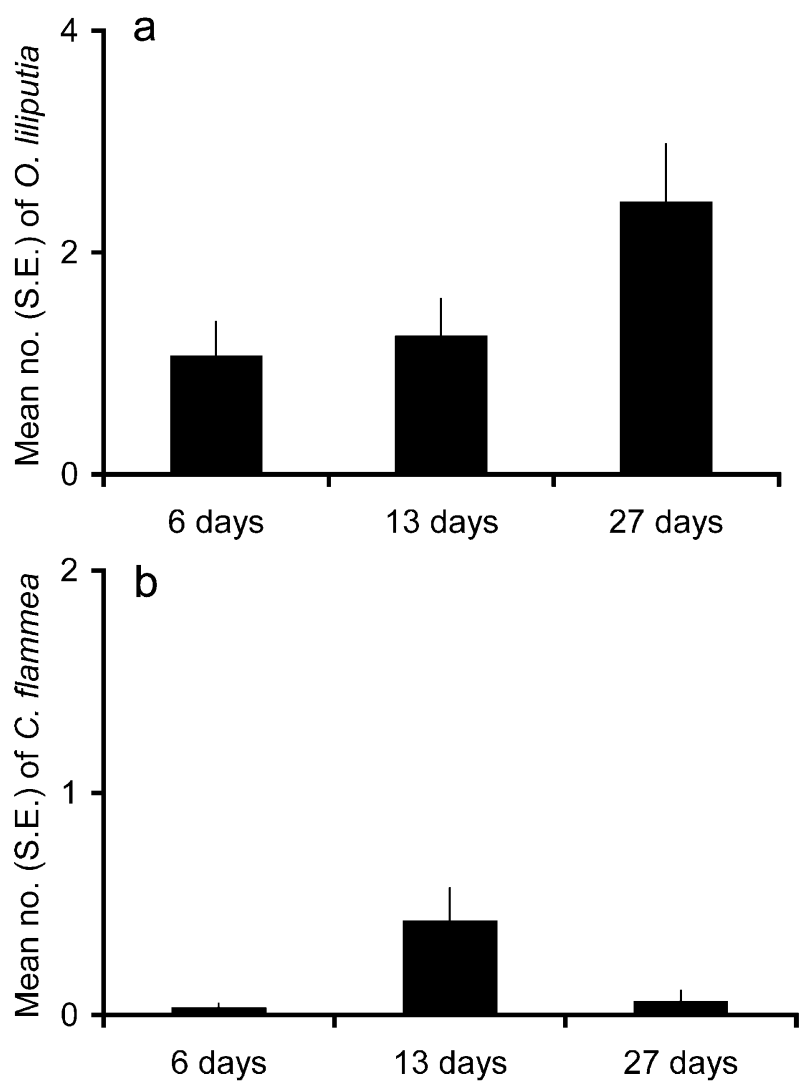

Fig. 3. Mean number $( \pm \mathrm{SE})$ of individuals $(n=2)$ through time. (a) O. liliputia averaged across treatments and plots, (b) C. flammea averaged across treatments in Plot 7.

tests, $P<0.05$; Plot 3, Fig. 2d). In addition, some patches had significantly larger abundances than natural turfs after 6 days, but densities dropped back levels of natural turfs after 13 days.

\subsection{Succession}

Successional patterns varied among patches as predicted, but trends were not consistent. Different patterns were observed in patches located the same distances from different plots, i.e. natural turfs and at different distances from the same plot. Nevertheless, two species, $E$. atropurpurea and $A$. incidata, were the first codominant colonizers in most patches with $S$. luteofuscus, E. rubrilabiata, and P. g. gregaria also relatively abundant (illustrated for patches located at 50 and $100 \mathrm{~cm}$ in Plot 7; Fig. 4a,b). Inconsistency in successional patterns was due mainly to the changes in abundances of S. luteofuscus, E. rubrilabiata, and P. g. gregaria across patches and plots. For example, S. luteofuscus peaked in the patches located at $100 \mathrm{~cm}$ in Plots 2 and 4 attaining similar abundances to E. atropurpurea and A. incidata 

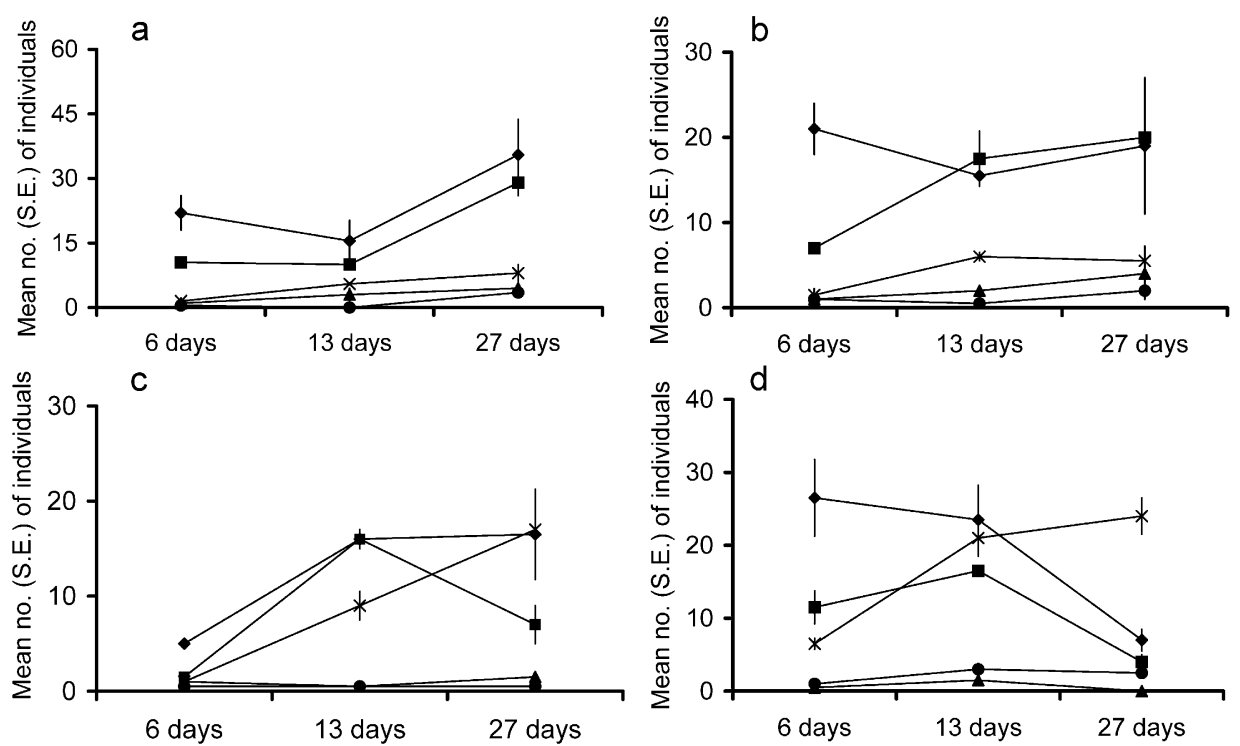

Fig. 4. Mean number ( \pm SE) of individuals $(n=2)$. (a) Patch located at $50 \mathrm{~cm}$ in Plot 7; (b) patch located at 100 $\mathrm{cm}$ in Plot 7; (c) patch located at $100 \mathrm{~cm}$ in Plot 2; (d) procedural control in Plot 2. ( ) E. atropurpurea, ( $\boldsymbol{\Delta})$ E. rubrilabiata, (৩) P. g. gregaria, (ロ) A. incidata, (*) S. luteofuscus.

(illustrated for patches located at $100 \mathrm{~cm}$ in Plot 2; Fig. 4c) and attained larger abundances than these two species in the procedural control in Plot 2 (Fig. 4d).

In addition, the fluctuations in abundances of species in the artificial patches did not match those found in the natural turfs. For example, E. atropurpurea arrived in all the patches, but did not reach natural turf levels in most of them (except Plot 2) during the experiment. After 27 days, E. rubrilabiata and P. g. gregaria peaked in some patches achieving significant larger abundances than in the natural turfs.

\section{Discussion}

The assemblages of microgastropods found in coralline turf are certainly not static (Olabarria and Chapman, 2002). Artificial turfs provide convenient, easily manipulated units to demonstrate that colonization of new habitat by microgastropods was rapid (i.e. within 6 days) for most species in most patches. The pattern (number of individuals) and mode (adults vs. juveniles) of colonization were generally independent of the proximity to a potential source of colonists, i.e. natural coralline turf. Most species responded differently between plots and artificial patches causing random patterns of colonization. The patterns of colonization were not always synchronous with, or in the same direction as, the changes in natural turf population levels, which themselves showed no consistent spatio-temporal pattern.

T. variabilis, C. flammea, E. rubrilabiata, P. olivacea, P. g. gregaria, and O. liliputia colonized all patches within 6 days, but the patterns of abundances were different. Some of 
these species reached similar abundances to the natural turf in all patches independently of distance from the algal turf, whereas other species did not, i.e. patterns of colonization varied among patches located at different distances. Furthermore, patterns of abundance varied from time to time, but this temporal variation was either consistent or inconsistent across plots, depending on the species examined. A. incidata and S. luteofuscus also colonized all patches within 6 days, but abundances in some patches were not stable through time. After 13 and 27 days, abundances of these species rose to greater numbers than found in the algal turfs. Finally, after 6 days, E. atropurpurea and A. contabulatum only colonized some patches reaching similar abundances to those in algal turf. Other patches were colonized after 13 or 27 days. Nevertheless, patterns of colonization for both species were not consistent across plots and time.

Artificial patches, including procedural controls, were rapidly colonized by most species, which often reached similar or larger abundances to those in natural turfs. These units rapidly trapped sediment (personal observation), which was expected to accumulate/change similarly across all treatments (no attempt was made to maintain sediment in these patches). Artificial patches provided a good habitat-mimic to test the stated hypotheses, except perhaps for E. atropurpurea. This species, which forms aggregations of hundreds of individuals in patches of coralline algae (Olabarria and Chapman, 2001a), was much more abundant in natural coralline turf (161.26 \pm 20.68 ; mean across plots and times) than in artificial patches $(17.49 \pm 1.28)$. E. atropurpurea appears to live on branches of coralline algae and probably feeds on microalgae and coralline branches (as inferred from the structure of its radulae; Beesley et al., 1998). Thus, artificial patches could have lacked a specific cue for E. atropurpurea, whereas the other species found a suitable sedimentary habitat within these patches. Olabarria and Chapman (2001b) showed that some of these species found in coralline algae survived and grew better in sediment, so sediment is likely to be an important component of coralline mats for some of them. Nevertheless, many gastropods respond to small-scale features of their habitats and aggregate in response to cues from the habitat and each other (Underwood and Chapman, 1992; Chapman and Underwood, 1994). Furthermore, aggregations can occur because of the complex responses of snails to a multitude of environmental factors, including topographic complexity, density of cospecifics and other species (Chapman, 1998). An alternative explanation could be that E. atropurpurea needs more time to attain similar abundances to those in natural turf because colonization is slow.

In addition, patterns of abundances observed in this study appeared to be biologically realistic since similar patterns of variability were observed in natural coralline turf at similar spatio-temporal scales (Olabarria and Chapman, 2001a, 2002). These artificial units, therefore, seem to be a reasonable surrogate for natural coralline turf and very useful for testing hypotheses about biological and environmental processes that cause such variation.

The number of colonizers did not increase or decrease consistently with the distance from the coralline algal turf ( $\leq 1 \mathrm{~m}$ ) for any single species. This does not agree with the "island biogeographic theory" of MacArthur and Wilson (1967), which predicts a decrease in the number of colonizers with the distance from the potential source of colonists. Some authors have demonstrated that distance of the patch from potentially colonizing organisms is an important factor influencing patch colonization in marine habitats (e.g. Sousa, 1984; Virnstein and Curran, 1986; Edgar, 1992), but this is not always the case (Menge et al., 
1993). The patterns of colonization in this study were not often synchronous with, or in the same direction as, the changes in abundances of the natural turfs. Although for T. variabilis, C. flammea, E. rubrilabiata, A. incidata, S. luteofuscus, and P. olivacea, patterns of colonization varied among patches consistently across plots of natural coralline turf, only T. variabilis, C. flammea, E. rubrilabiata, and $P$. olivacea showed a close relationship between abundances in natural algal turf and abundances in patches. For example, abundances of $A$. incidata and $S$. luteofuscus in many patches were significantly larger than those in natural turfs.

These results suggest that the nearest plot of coralline algal turf was not probably the source of colonists for the patches. This evidence does not support a limited-dispersal hypothesis (e.g. Dayton, 1973; Paine, 1988), at least over short distances. No dispersal limitation was evident among patches, nor among plots, which were at least $6 \mathrm{~m}$ away from each other.

Patterns of benthic colonization have been shown to be variable in soft-sediments (Santos and Simon, 1980; Zajac and Whitlatch, 1982), hard substrata (Kay and Keough, 1981; Keough, 1984) and seagrasses (Virnstein and Curran, 1986; Edgar, 1992). Variability in colonization may be explained by abiotic and biotic patterns affecting ambient hydrodynamics and, hence, the production and supply of colonists (Zajac and Whitlatch, 1982). For example, the location of a patch with respect to various environmental gradients (tidal height, wave exposure, current velocity, degree of insolation) can directly affect patterns and rate of colonization (see, e.g. Denley and Underwood, 1979; Paine, 1979; Sousa, 1985; Benedetti-Cecchi and Cinelli, 1994). In addition, most of the species in this study are thought to feed on microalgae, diatoms, and detritus (Beesley et al., 1998), and their food resources could be affected by processes such as sedimentation, resuspension, and transport of particulate organic matter (Zajac and Whitlatch, 1982).

Although stages in the life cycle (adults vs. juveniles) have been long recognized to play an important role in colonization and succession in soft-bottoms (e.g. Levin, 1984; Zajac et al., 1998) and in rocky intertidal shores (e.g. Dayton, 1975; Sousa, 1980), it does not appear to be in this case. Adults and juveniles of most species colonized patches independently of the distance to the natural turf (see Table 4), exhibiting similar patterns. Juveniles and adults colonizing different patches were likely to come from a mixed of patches of algal turf (e.g. patterns of E. atropurpurea) and dispersed over scales of meters.

Crawling may be a mechanism enabling microgastropods to colonize patches next to the algal turf although there is no evidence of microgastropods crawling on bare rock. The observed patterns of colonization with a strong stochastic component of spatio-temporal variation are likely to be related to fast rates of dispersal of these microgastropods. Previous studies on the dispersal rates of small organisms (Highsmith, 1985; Commito et al., 1995; Cummings et al., 1995; Martel and Chia, 1991; Norkko et al., 2001) have shown that can disperse as juveniles and adults by drifting and/or floating in the water column. Norkko et al. (2001) showed that juvenile bivalves from soft-bottoms dispersed over scales of meters possibly following a Brownian motion. Whether or not dispersal is passive or active, net effects are likely to correlate with the hydrodynamic regime. Thus, wind, waves, and bedload transport may be important factors affecting the dispersal of these organisms (Grant et al., 1997; Turner et al., 1997). In addition, if dispersal is rapid, local interactions, such as predation or competition are likely to be overwhelmed by immigra- 
tion and emigration (Palmer et al., 1996). Previous work has shown different rates of growth and survival of some of these species in different types of algal sediment habitat (Olabarria and Chapman, 2001b). These organisms might also actively select different patches of habitat, thereby altering patterns of colonization created by physical processes only (e.g. Hannan, 1984; Butman, 1987; Snelgrove et al., 1993). If the cues used for immigration were themselves patchy in time and space, this would add to the unpredictability of patterns of abundance.

The large differences in abundances colonizing new patches of similar quality of habitat within the same plot could indicate that post-colonization processes (e.g. competition, predation, disturbance, immigration/emigration, etc.) are important in determining patterns of spatial distribution of these organisms, even over very short periods of time. Other studies in marine systems have, however, demonstrated that community assemblages in newly opened habitat are often highly variable and unpredictable (Hall et al., 1994). Serial stages are rarely obvious and differences in the pattern of succession highlight the importance of dispersal and the supply of colonists (Palmer et al., 1996).

Although most species colonized quickly (within 6 days), which is common to mat-like habitats in rocky shores (Myers and Southgate, 1980), their abundances varied greatly through time. The temporal differences were not usually synchronous with changes in natural populations, but were complex, varying among both patches and plots. Such temporal variability in colonization is common for organisms on rocky shores (Loosanoff, 1964; Menge, 1991; Hunt and Scheibling, 1998; Jeffery, 2000). Many initial colonizers exhibit an overshoot pattern during the colonization process, i.e. a rapid initial colonization with abundances increasing to significantly higher levels than the controls and then declining to control levels (Martin-Smith, 1994; Beukema et al., 1999; Lu and Wu, 2000). In this study, none of the species, however, showed this overshoot pattern. Thus, although E. atropurpurea were early colonizers, they did not reach the densities found naturally in turf (except in Plot 2) during the experiment. In contrast, after 27 days, abundances of $A$. incidata (which were also early colonists) rose to significantly greater numbers than found in natural turfs. Furthermore, the lack of a monotonic pattern of colonization, i.e. a steady increase of abundance over time, for most species suggest that individuals arrived and left patches randomly through time.

In summary, the ability of these microgastropods to colonize new habitats quickly and over distances of meters has important implications for our understanding of the functioning of benthic assemblage in patchy habitats. The patchy distribution of microgastropods in coralline turf (Olabarria and Chapman, 2001a) is dependent on the colonization process, which is itself variable in space. Post-colonization processes (e.g. predation, competition, selection of habitat, disturbance, immigration/emigration, etc.) may, however, play an important role in maintaining this mosaic pattern in coralline turf (Olabarria and Chapman, 2001a). Determining the relative importance of different types of colonists is essential to understanding the causes of spatial and temporal variability of benthic assemblages, not only for the development of ecological theory (Roughgarden et al., 1985), but also for management purposes (Kennelly and Underwood, 1992). Furthermore, the long-term ability of a species to survive in patchy habitats depends on its ability to disperse, thereby allowing gene flow and (re)colonization of habitat patches (Harrison et al., 1988). Therefore, studies aimed to measure the rate and dispersal ability of 
organisms are critical to predicting recovery and how this may vary across different spatial scales.

\section{Acknowledgements}

This research was supported by funds from the Australian Research Council, the Institute of Marine Ecology and the Centre for Research on Ecological Impacts of Coastal Cities. I am grateful to Sonia Monteiro, Elena Lazzarotto, David Blockley, Francesca Rossi for their help in the field and also to Grant Kaplan and Andrés Grigaliunas who helped with sorting in the laboratory. This paper also benefited from comments by Gee Chapman and Theresa Lasiak. [RW]

\section{References}

Akioka, H., Baba, M., Masaki, T., Johansen, H.W., 1999. Rocky shore turfs dominated by Corallina (Corallinales, Rhodophyta) in northern Japan. Phycol. Res. 47, 199-206.

Barnes, R.S.K., 1998. The effects of movement on population density estimates of mudflat epifauna. J. Mar. Biol. Assoc. UK 78, 377-385.

Barry, J.P., Dayton, P.K., 1991. Physical heterogeneity and the organization of marine communities. In: Kolasa, J., Pickett, S.T.A. (Eds.), Ecological Heterogeneity. Springer, New York, pp. 270-320.

Beesley, P.L., Ross, G.J.B., Wells, A., 1998. Mollusca: The Southern Synthesis. Fauna of Australia, vol. 5. CSIRO, Melbourne. Part A xvi 563 pp. Part B viii 565-1234 pp.

Bell, S.S., Devlin, D.J., 1983. Short-term macrofaunal recolonization of sediment and epibenthic habitats in Tampa Bay, Florida Bull. Mar. Sci. 33, 102-108.

Bell, S.S., Hicks, G.R.F., 1991. Marine landscapes and faunal recruitment: a field test with seagrasses and copepods. Mar. Ecol., Prog. Ser. 73, 61-68.

Benedetti-Cecchi, L., Cinelli, F., 1994. Recovery of patches in an assemblage of geniculate coralline algae: variability at different successional stages. Mar. Ecol., Prog. Ser. 110, 9-18.

Beukema, J.J., Flach, E.C., Dekker, R., Starink, M., 1999. A long-term study of recovery of the macrozoobenthos on large defaunated plots on a tidal flat in the Wadden Sea. J. Sea Res. 42, 235-254.

Butler, A.J., 1991. Effect of patch size on communities of sessile invertebrates in Gulf St. Vincent, South Australia. J. Exp. Mar. Biol. Ecol. 153, 225-280.

Butman, C.A., 1987. Larval settlement of soft-sediment invertebrates: the spatial scales of pattern explained by active habitats selection and the emerging role of hydrodynamical processes. Oceanogr. Mar. Biol., Annu. Rev. 25, 113-165.

Chapman, M.G., 1998. Variability in trail-following and aggregation in Nodilittorina unifasciata Gray. J. Exp. Mar. Biol. Ecol. 224, 49-71.

Chapman, M.G., Underwood, A.J., 1994. Dispersal of the intertidal snail Nodilittorina pyramidalis, in response to the topographic complexity of the substratum. J. Exp. Mar. Biol. Ecol. 179, 145-169.

Commito, J.A., Currier, C.A., Kane, L.R., Reinsel, K.A., Ulm, I.M., 1995. Dispersal dynamics of the bivalve Gemma gemma in a patchy environment. Ecol. Monogr. 65, 1-20.

Cummings, V.J., Pridmore, R.D., Thrush, S.F., Hewitt, J.E., 1995. Post-settlement movement by intertidal benthic macroinvertebrates: do common New Zealand species drift in the water column? N.Z. J. Mar. Freshw. Res. 29, 59-67.

Davenport, J., Stevenson, T.D.I., 1998. Intertidal colonization rates. A matched latitude, north v. south, remote v. near shore island experiment. Divers. Distrib. 4, 87-92.

Dayton, P.K., 1973. Dispersion, dispersal and persistence of the annual intertidal alga, Postelsia palmaeformis Ruprecht. Ecology 54, 433-438. 
Dayton, P.K., 1975. Experimental evaluation of ecological dominance in a rocky intertidal algal community. Ecol. Monogr. 45, 137-159.

Dayton, P.K., Tegner, M.J., 1984. Catastrophic storms, El Niño, and patch stability in a southern California kelp community. Science 224, 283-285.

Dayton, P.K., Tegner, M.J., Parnell, P.E., Edwards, P.B., 1992. Temporal and spatial patterns of disturbance and recovery in a kelp forest community. Ecol. Monogr. 62, 421-445.

Dean, R.L., Connell, J.H., 1987a. Marine invertebrates in algal succession: I. Variations in abundance and diversity with succession. J. Exp. Mar. Biol. Ecol. 109, 195-215.

Dean, R.L., Connell, J.H., 1987b. Marine invertebrates in algal succession: II. Tests of hypotheses to explain diversity with succession. J. Exp. Mar. Biol. Ecol. 109, 217-247.

Denley, E.J., Underwood, A.J., 1979. Experiments on factors influencing settlement, survival and growth of two species of barnacles in New South Wales. J. Exp. Mar. Biol. Ecol. 36, 269-293.

Edgar, G.J., 1991. Artificial algae as habitats for mobile epifauna: factors affecting colonization in a Japanese Sargasum bed. Hydrobiologia 226, 111-118.

Edgar, G.J., 1992. Patterns of colonization of mobile epifauna in a Western Australian seagrass bed. J. Exp. Mar. Biol. Ecol. 157, 225-246.

Farrell, T.M., 1991. Models and mechanisms of succession: an example from a rocky intertidal community. Ecol. Monogr. 61, 95-113.

Gee, J.M., Warwick, R.M., 1996. A study of global biodiversity patterns in the marine motile fauna of hard substrata. J. Mar. Biol. Assoc. UK 76, 177-184.

Grant, J., Turner, S.J., Legendre, P., Hume, T.M., Bell, R.G., 1997. Spatio-temporal patterns of sediment transport on an intertidal sandflat, Manukau Harbour, New Zealand. J. Exp. Mar. Biol. Ecol. 216, 35-50.

Günther, C.P., 1992. Dispersal of intertidal invertebrates: a strategy to react to disturbances of different scales? Neth. J. Sea Res. 30, 45-56.

Hall, S.J., Raffaelli, D., Thrush, S.F., 1994. Patchiness and disturbance in shallow water benthic assemblages. In: Hildrew, A.G., Giller, P.S., Raffaelli, D. (Eds.), Aquatic Ecology: Scale, Pattern and Processes. Blackwell, Oxford, England, pp. 333-375.

Hannan, C.A., 1984. Planktonic larvae may act like passive particles in turbulent near-bottom flows. Limnol. Oceanogr. 29, $1108-1116$.

Harrison, S., Murphy, D.D., Ehrlich, P.R., 1988. Distribution of the Bay Checkerspot Butterfly. Euphydryas editha bayensis: evidence for a metapopulation model. Am. Nat. 132, 360-382.

Highsmith, R.C., 1985. Floating and algal rafting as potential dispersal mechanisms in brooding invertebrates. Mar. Ecol., Prog. Ser. 25, 169-179.

Hockey, P.A.R., Schurink, C.V., 1992. The invasive biology of the mussel Mytilus galloprovincialis on the southern African coast. Trans. R. Soc. S. Afr. 48 (1), 123-139.

Howard, R.K., 1985. Measurements of short-term turnover of epifauna within seagrass beds using an in situ staining method. Mar. Ecol., Prog. Ser. 22, 163-168.

Hunt, H.L., Scheibling, R.E., 1998. Spatial and temporal variability of patterns of colonization by mussels (Mytilus trossulus, M. edulis) on a wave-exposed rocky shore. Mar. Ecol., Prog. Ser. 167, 155-169.

Jeffery, C.J., 2000. Settlement in different-sized patches by the gregarious intertidal barnacle Chamaesipho tasmanica Foster and Anderson in New South Wales. J. Exp. Mar. Biol. Ecol. 252, 15-26.

Johannesson, K., 1988. The paradox of Rockall: why is a brooding gastropod Littorina saxatilis more widespread than one having a planktonic larval stage Littorina littorea. Mar. Biol. 99, 504-514.

Kay, A.M., Keough, M.J., 1981. Occupation of patches in the epifaunal communities on pier pilings and the bivalve Pinna bicolor at Edithburgh, South Australia. Oecologia 48, 123-130.

Kelaher, B., 2000. Biodiversity of macrofaunal assemblages in coralline algal turf. PhD thesis, University of Sydney, Sydney, Australia.

Kennelly, S.J., Underwood, A.J., 1992. Fluctuations in the distributions and abundances of species in sublittoral kelp forests in New South Wales. Aust. J. Ecol. 17, 367-382.

Keough, M.J., 1984. Effects of patch size on the abundance of sessile marine invertebrates. Ecology 65, 423437.

Lagadeuc, Y., Colbeaux, J.P., 1992. Effects of the mineral composition of rocks on colonization by the polychaete annelid Polydora ciliata Johnston 1828. Cah. Biol. Mar. 33 (2), $13-146$. 
Leber, K.M., 1985. The influence of predatory decapods, refuge, and microhabitat selection on seagrass communities. Ecology 66, 1951-1964.

Levin, L.A., 1984. Life history and dispersal patterns in a dense infaunal polychaetes assemblage: community structure and response to disturbance. Ecology 65, 1185-1200.

Levin, S., 1992. The problem of patterns and scale in ecology. Ecology 73, 1943-1967.

Loosanoff, V.I., 1964. Variation in time and intensity of setting of the starfish Asterias forbesi in Long Island Sound during a twenty-five year period. Biol. Bull. 126, 423-439.

Lu, L., Wu, R.S.S., 2000. An experimental study on recolonization and succession of marine macrobenthos in defaunated sediment. Mar. Biol. 136, 291-302.

MacArthur, R.H., Wilson, E.O., 1967. The Theory of Island Biogeography. Princeton Univ. Press, Princenton, NJ, USA, p. 216.

Martel, A., Chia, F.-S., 1991. Drifting and dispersal of small bivalves and gastropods with direct development. J. Exp. Mar. Biol. Ecol. 150, 131-147.

Martin-Smith, K.M., 1994. Short-term dynamics of tropical macroalgal epifauna: patterns and processes in recolonization of Sargasum fissifolium. Mar. Ecol., Prog. Ser. 110, 177-185.

McGuinness, K.A., 1988. Short-term effects of sessile organisms on colonization of intertidal boulders. J. Exp. Mar. Biol. Ecol. 116 (2), 159-176.

Menge, B.A., 1991. Relative importance of recruitment and other causes of variation in rocky intertidal community structure. J. Exp. Mar. Biol. Ecol. 146, 69-100.

Menge, B.A., Farrell, T.M., Olson, A.M., van Tamelen, P., Turner, T., 1993. Algal recruitment and the maintenance of a plant mosaic in the low intertidal region on the Oregon coast. J. Exp. Mar. Biol. Ecol. 170, 91-116.

Myers, A.A., Southgate, T., 1980. Artificial substrates as means of monitoring rocky shore cryptofauna. J. Mar. Biol. Assoc. UK 60, 963-975.

Norkko, A., Cummings, V.J., Thrush, S.F., Hewitt, J.E., Hume, T., 2001. Local dispersal of juvenile bivalves: implications for sandflat ecology. Mar. Ecol., Prog. Ser. 212, 131-144.

Ohlhorst, S.L., 1982. Diel migration patterns of demesral reef zooplankton. J. Exp. Mar. Biol. Ecol. 60, $1-16$.

Olabarria, C., Chapman, M.G., 2001a. Comparison of patterns of spatial variation of species of microgastropods between two contrasting intertidal habitats. Mar. Ecol., Prog. Ser. 220, 201-211.

Olabarria, C., Chapman, M.G., 2001b. Habitat-associated variability in survival and growth of three species of microgastropods. J. Mar. Biol. Assoc. UK 81, 961-966.

Olabarria, C., Chapman, M.G., 2002. Inconsistency in short-term temporal variability of microgastropods within and between two different intertidal habitats. J. Exp. Mar. Biol. Ecol. 269, 85-100.

Paine, R.T., 1979. Disaster, catastrophe, and local persistence of sea palm Postelsia palmaeformis. Science 205, 685-687.

Paine, R.T., 1988. Habitat suitability and local populations persistence of the sea palm Postelsia palmaeformis. Science 205, $1787-1794$.

Paine, R.T., Levin, S.A., 1981. Intertidal landscapes: disturbance and the dynamics of pattern. Ecol. Monogr. 51, 145-178.

Palmer, M.A., Allan, D.J., Butman, C.A., 1996. Dispersal as a regional process affecting the local dynamics of marine and stream benthic invertebrates. TREE 11, 322-326.

Roughgarden, J., Iwasa, Y., Baxter, C., 1985. Demographic theory of an open marine population with spacelimited recruitment. Ecology 66, 54-67.

Santos, S.L., Simon, J.L., 1980. Marine soft-bottom community establishment following annual defaunation: larval or adult recruitment? Mar. Ecol., Prog. Ser. 2, 235-241.

Sherman, K.M., Coull, B.C., 1980. The response of meiofauna to sediment disturbance. J. Exp. Mar. Biol. Ecol. 46, 59-71.

Smith, C.R., Brumsickle, S.J., 1989. The effect of patch size and substrate isolation on colonization modes and rate in an intertidal sediment. Limnol. Oceanogr. 34, 1263-1277.

Smith, S.D.A., Simpson, R.D., 1993. Effects of pollution on holdfast macrofauna of the kelp Ecklonia radiata: discrimination at different taxonomic levels. Mar. Ecol., Prog. Ser. 96, 199-208.

Snelgrove, P.V.R., Butman, C.A., Grassle, J.P., 1993. Hydrodynamic enhancement of larval settlement in the bivalve Mulinia lateralis (Say) and the polychaete Capitella sp: I. In microdepositional environments. J. Exp. Mar. Biol. Ecol. 168, 71-109. 
Sörlin, T., 1988. Floating behaviour in the tellinid bivalve Macoma balthica (L.). Oecologia 77, 273-277.

Sousa, W.P., 1980. The response of a community to disturbance: the importance of successional age and species' life histories. Oecologia 45, $72-81$.

Sousa, W.P., 1984. Intertidal mosaic: patch size, propagule availability, and spatially variable patterns of succession. Ecology 65, 1918-1935.

Sousa, W.P., 1985. Disturbance and patch dynamics on rocky intertidal shores. In: Pickett, S.T.A., White, P.S. (Eds.), The Ecology of Natural Disturbance and Patch Dynamics. Academic Press, London, pp. 101-124.

Stewart, J.G., 1982. Anchor species and epiphytes in intertidal algal turf. Pac. Sci. 36, 45-59.

Thrush, S.F., Whitlatch, R.B., Pridmore, R.D., Hewitt, J.E., Cummings, V.J., Wilkinson, M.R., 1996. Scaledependent recolonization: the role of sediment stability in a dynamic sandflat habitat. Ecology 77, 2472 2487.

Turner, S.J., Grant, J., Pridmore, R.D., Hewitt, J.E., Wilkinson, M.R., Hume, T.M., Morrisey, D.J., 1997. Bedload and water-column transport and colonization processes by post-settlement benthic macrofauna: does infaunal density matter? J. Exp. Mar. Biol. Ecol. 216, 51-75.

Underwood, A.J., 1999. History and recruitment in structure of intertidal assemblages on rocky shores: an introduction to problems for interpretation of natural change. In: Whitfield, M. (Ed.), Aquatic Life Cycle Strategies. Institute of Biology, London, pp. 79-96.

Underwood, A.J., Chapman, M.G., 1992. Experiments on topographic influences on density and dispersion of Littorina unifasciata in New South Wales. In: Grahame, J., Mill, P.J., Reid, D.G. (Eds.), Proceedings of the Third International Symposium on Littorinid Biology. Malacological Society of London, London, pp. 185 195.

Underwood, A.J., McFadyen, K.E., 1983. Ecology of the intertidal snail Littorina acutispira Smith. J. Exp. Mar. Biol. Ecol. 66, 169-197.

Van Blaricom, G.R., 1982. Experimental analysis of structural regulation in a marine sand community exposed to oceanic swell. Ecol. Monogr. 52, 283-305.

Virnstein, R.W., Curran, M.C., 1986. Colonization of artificial seagrass vs. time and distance from source. Mar. Ecol., Prog. Ser. 29, 279-288.

Warwick, R.M., 1993. Environmental impact studies on marine communities: pragmatical considerations. Aust. J. Ecol. 18, 63-80.

Winer, B.J., 1971. Statistical Principles in Experimental Designs, 2nd edn. McGraw-Hill Kogakusha, Tokyo, p. 907.

Zajac, R.N., Whitlatch, R.B., 1982. Responses of estuarine infauna to disturbance: II. Spatial and temporal variation of succession. Mar. Ecol., Prog. Ser. 10, 15-27.

Zajac, R.N., Whitlatch, R.B., Thrush, S.F., 1998. Recolonization and succession in soft-sediment infaunal communities: the spatial scale of controlling factors. Hydrobiologia 375/376, 227-240. 